\title{
Supporting Transgender Students in Higher Education: Opportunities for Mental Health Professionals
}

\author{
Tracy G. Marsh \\ Walden University
}

\begin{abstract}
During the last decade, there has been a significant increase in visibility of transgender and gender-nonconforming (TGNC) individuals, particularly in Western cultures. However, this increase in visibility has also prompted a concomitant surge in hate crimes and violence against TGNC persons and anti-TGNC legislation throughout the United States. Extant research, framed largely by Meyer's minority stress model, has shown that TGNC persons experience greater rates of psychological distress, including depression, anxiety, substance abuse, and suicidal ideation and intent when compared to cisgender and lesbian, gay, and bisexual peers. Furthermore, TGNC students in higher education face specific challenges with regard to campus facilities, housing, athletics, management of their preferred gender identity, and scholarly research. Mental health professionals with explicitly stated ethical imperatives toward advancing diversity, multiculturalism, and social change are uniquely positioned to advocate on behalf of TNGC higher education students. The purpose of this scholarly essay is to summarize challenges faced by TGNC students and to identify specific ways that mental health professionals can effect change on the campus, in the classroom, in research, and in direct service.
\end{abstract}

Keywords: transgender, TGNC, university, students, psychologists, mental health

\section{Hidden Struggles}

In the film Hidden Figures (Chernin \& Melfi, 2016), research mathematician Katherine Johnson runs through a heavy downpour to the only available "colored bathroom" situated across the sprawling NASA campus. Presumably, we feel some relief knowing that this practice of institutional racial segregation and prejudice has since been outlawed. Indeed, the civil rights movement has made substantive progress in advancing the rights of ethnic minorities over the last 50 years. Similar progress is also evident on behalf of the gay and lesbian community following the gay liberation moment that emerged in the 1970s. However, transgender and gender nonconforming (TGNC) persons have largely been excluded from these social change movements and continue to face significant barriers in their personal and professional lives (Grant, Mottet, Tanis, \& Min, 2011; Testa, Jimenez, \& Rankin, 2014).

Within the last decade, a number of high-profile TGNC persons such as Caitlin Jenner, Laverne Cox, Chaz Bono, Janet Mock, and Jazz Jennings have increased the overall visibility and awareness of the TGNC community (Kanamori, Cornelius-White, Pegors, Daniel, \& Hulgus, 2017). However, this increased awareness has also seemingly triggered a disturbing increase in rates of verbal and physical abuse, sexual assault, and rape against members of the TGNC community (Bockting et al., 2013; Hendricks \& Testa, 2012; James et al., 2016). Federal and state crime statistics from the last several years have revealed record numbers of homicides of transmen and transwomen in the United States, with 2016 surpassing 2015 for the most homicides in a single year (Schmider, 2016). 
Everyday challenges to TGNC individuals extend to higher education settings, where finding a safe restroom is only one of the often-invisible struggles encountered on college campuses. For TGNC students, barriers to accessing a single-stall or gender-neutral restroom often results in coping behaviors such as restricting food and water intake (which can lead to dehydration and kidney and urinary tract infections), skipping classes, or dropping out of college altogether (Seelman, 2016).

\section{The Impact of Stigma, Discrimination, and Bias}

Broadly, research findings have been consistent regarding the increased rates and concomitant risks of gender-based discrimination and bias against TGNC persons (Cannon et al., 2017). For example, James et al. (2016) found that serious psychological distress is reported in $39 \%$ of the TGNC population (compared to roughly $5 \%$ for nontransgendered persons), and suicide attempts are reported in $40 \%$ of the population, nearly eight times the rate of cisgender persons (those individuals whose gender identity is consistent with the sex assigned to them at birth). The authors also noted that poverty rates are twice the national average, and unemployment rates are nearly triple. Rates of depression among transgender women have been reported at roughly five to seven times the general U.S. population (Budge, Adelson, \& Howard, 2013). Nearly one in four TGNC persons has been homeless at some point in his or her lifetime (Bradford, Reisner, Honnold, \& Xavier, 2013). TGNC persons face increased likelihood of discrimination and harassment in the workplace (Brewster, Velez, Mennicke, \& Tebbe, 2014) and when seeking housing and medical care (Grant et al., 2011). Perhaps even more disturbing, TGNC persons of color, those with disabilities, and those with undocumented residency status are at even greater risk for discrimination and violence (Grant et al., 2011; Seelman, 2016).

\section{Minority Stress Model}

It is important to note that the serious mental health challenges TGNC persons face are not necessarily due to their gender identity, but may be significantly related to minority stress as a result of chronic discrimination and bias (American Psychological Association [APA], 2015). Meyer's (2015) minority stress model, originally developed to explain the impact of extreme stress due to systematic oppression of sexual minorities, was subsequently expanded to specifically address the unique challenges faced by gender minorities. Meyer's minority stress model is based on two key assumptions - that TGNC persons face unique stressors due to their gender identity status and that these stressors (both proximal and distal) have severe negative mental and physical health consequences. These can include depression, anxiety, substance use disorders, and eating disorders (Carmel \& Erickson-Schroth, 2016; Connolly, Zervos, Barone, Johnson, \& Joseph, 2016). Supporting Meyer's model are data that show psychiatric illness among TGNC persons surpassing that of both cisgender as well as gay, lesbian, and bisexual persons (Bariola et al., 2015).

In contrast to many deficit-based models of TGNC persons, Meyer's minority stress model highlights the critical protective factors of individual and community-based resilience among sexual and gender minorities in combating institutionalized discrimination (Meyer, 2015). Support for this model has been demonstrated through research that shows improved psychological health through contact with other TGNC persons and development of positive gender identity (Bariola et al., 2015; Bockting et al., 2013), exposure to trans-affirming community and positive relationships with family (Singh, Meng, \& Hansen, 2014), and development of trans-inclusive educational institutions (Zeeman, Aranda, Sherriff, \& Cocking, 2017). 


\section{The Hidden " $T$ " in Research}

Despite the broad interest in lesbian, gay, bisexual, and transgender (LGBT) issues within social science research, studies that specifically examine the "T" and do not simply subsume this population under the larger lesbian, gay, and bisexual (LGB) umbrella are more recent (Kite \& Bryant-Lees, 2016). Failing to disaggregate TGNC data from LGB data effectively removes the TGNC population from the findings, which in some cases (e.g., research on HIV prevalence, risk, and prevention) severely limits the applicability and potential positive benefit to the TGNC community (APA, 2015). The practice of collapsing the T into the LGB findings extends to research on students' experiences in college; most have included a very small subsample of TGNC students, if any (APA, 2015). Additionally, studies that include sex or gender as a demographic variable typically limit the response options to "male" or "female" (Cahill \& Makadon, 2014; Deutsch \& Buchholz, 2015), further silencing the TGNC community and limiting the applicability of findings.

\section{TGNC Persons on Campus}

North Carolina's so-called bathroom debate and accompanying legislative efforts to require TGNC persons to use restrooms in accordance with their assigned gender amplifies an already hostile education environment in which TGNC persons face disproportionately high levels of verbal and physical abuse, psychological distress, and lack of support from peers, faculty, and administration (Johnston, 2016; Woodford et al., 2018). In February, 2017, the Departments of Justice and Education under the Trump Administration rescinded guidance on Title IX with regard to TGNC students' access to school restrooms and locker rooms, effectively delegating policy making to individual states and school districts (Baker, 2017).

The college campus presents other challenges and barriers for TGNC students. In addition to finding a safe and accessible bathroom, TGNC students encounter student housing policies that may not acknowledge or account for their gender identity and result in housing placement based on their assigned sex (Nicolazzo, 2016; Nicolazzo \& Marine, 2015). Campus sports can present a barrier, as most team sports are "gendered" and TGNC students may face questions of fairness or appropriateness when attempting to participate based on their gender identity (Gray, Crandall, \& Tongsri, 2018; Morris \& Van Raalte, 2016). Locker rooms with communal shower and dressing areas that require public nakedness may feel unsafe, and many TGNC students report avoiding using outdoor walking or running trails due to fear of assault (Seelman, 2016). For many TGNC students, attendance roll call may present a particularly difficult moment when their name of record does not match their gender identity and presentation. In many of these instances, TGNC students do not have the option of "coming out" or self-identifying; it is forced upon them (Singh, Meng, \& Hansen, 2013). TGNC students, particularly those of color, those who are disabled, or those from a lower socioeconomic status, are at significant risk for abandoning their education (James, et al., 2016). Finally, denial of access to campus restrooms and campus housing has been shown to correlate with higher rates of attempted suicide (Seelman, 2016).

Collectively, the negative impact of a hostile education environment is far reaching; TGNC persons who decide or are forced to leave their education tend to have higher rates of poverty, homelessness, underground employment (e.g., sex work), incarceration, substance abuse, HIV infection, and suicide (Grant et al., 2011). Considering the overwhelming evidence of the deleterious impact of transnegative education environments, a clarion call exists for mental health professionals to lead efforts to transform our educational institutions to support and affirm the TGNC community (BrckaLorenz, Garvey, Hurtado \& Latopolski, 2017). 


\section{The Ethical Mandate to Advocate}

There is a critical nexus between the decade-over-decade growth in college attendance (Snyder, de Brey, \& Dillow, 2016), increased visibility of transgendered identities, and growing evidence of the deleterious impact of TGNC discrimination (Bouman, Davey, Meyer, Witcomb, \& Arcelus, 2016). Psychologists, mental health counselors, and social workers have a unique opportunity to support and advocate on behalf of TGNC students. The ethical codes for each of these professions incorporate foundational principles that speak to promoting integrity, social justice, and diversity (American Counseling Association, 2014; APA, 2002; National Association of Social Workers, n.d.). As such, there is an ethical imperative to understand and meet the specific needs of TGNC students.

Meyer's (2015) minority stress model emphasizes that support from peers and faculty can have a profound impact in developing resilience among TGNC students (Pryor, 2015; Seelman, 2016). Faculty primarily set the tone in class and having an instructor who is publicly supportive of TGNC identities trickles down to how cisgender students treat their TGNC classmates. TGNC students perceive social science and women's studies courses to be more TGNC friendly, while science, technology, engineering, and mathematics courses are more "chilly" (Pryor, 2015, p. 452); this presents an opportunity for mental health faculty to focus specifically on educating faculty in science, technology, engineering, and mathematics disciplines about the TGNC population and how best to support them in class. Additionally, incorporating experiential learning that includes direct interactions with and personal narratives of TGNC persons has been shown to positively impact attitudes held by cisgender students (Green, 2014).

The APA and the American Counseling Association have authored specific guidelines and competencies for working with TGNC individuals (APA, 2015, Burnes, 2010). These guidelines have evolved largely from the growing body of contemporary TGNC research and the World Professional Association for Transgender Health Standards of Care (Coleman et al., 2012). Using these guidelines as a foundational springboard, the following suggestions are offered to effect positive change towards creating TGNC affirmative campus environments.

At the campus/administration level:

- Advocate for a policy that allows students to request a name change in their official record that is in accordance with their identified gender

- Work with student affairs offices and LGBT resource centers to make available genderneutral and/or single-stall restrooms in locations throughout the campus

- Collaborate with campus administration to accommodate TGNC student housing needs; provide options for gender-neutral participant sports and locker rooms with private showers and dressing areas

- Request professional development training for faculty and staff that addresses the specific needs of TGNC students and that is not simply "bundled into" LGB training

- Advocate for campus health centers to provide services that support gender transition efforts

In classrooms:

- Discontinue attendance roll call; allow students to sign in and indicate their preferred name and salutation 
- Examine our curriculum to identify assumptions of binary gender and replace with innovative ways for students to critically examine gender assumptions

- When applicable, include personal narratives/autobiographies and rich media in the curriculum to help cisgender students understand and appreciate the TGNC experience

- Include a statement in class syllabi establishing a tone of respect for diverse gender identities

- Avoid asking personal questions of TGNC students; it is not their responsibility to educate cisgender peers and faculty

In faculty research and when mentoring student research:

- Offer expanded gender categories beyond male and female when collecting demographic data

- Educate institutional review board panels regarding the unique considerations inherent in research on TGNC issues

- Identify and share information about secondary datasets that have good representation of TGNC participants

- Create opportunities to connect faculty and students across disciplines; the overall body of research on TGNC issues is relatively scant and there are rich opportunities through interdisciplinary collaboration with peers from allied field such as public health, public policy, nursing, education, and social work

When working clinically with TGNC persons:

- Work with campus counseling centers to ensure staff are competent to provide mental health services to TGNC students and to develop training for those who do not yet have these competencies

- Ensure that clinical interventions are evidence based and reflect the most current guidelines for treatment with TGNC clients

- Do not assume that the primary treatment focus for TGNC clients is their gender identity and/or transition

Findings from the small but growing body of research on the impact of negative campus climate on TGNC college students are quite consistent: poorer mental health, greater isolation and likelihood of dropping out of class or school, and suicidality (Bariola et al., 2015; Seelman, 2016; Woodford et al., 2018). However, Meyer's minority stress model has been pivotal in expanding the focus of attention from the individual to the environment, and highlighting the role of resilience in coping and succeeding in the face of systemic oppression and discrimination (Meyer, 2015). Recent equal access educational policy efforts in Australia incorporate many of the suggestions noted earlier, and early research shows that TGNC students benefitted significantly from social support, inclusive curricula, and a strength-based, rather than deficit model of gender nonconformity (Jones, 2017). California, an early leader in support of TGNC students in K-12 education, has recently passed legislation that will require specific actions by schools to better support these students (Meyer \& Keenan, 2018). Although challenges in achieving policy compliance across districts has been observed, the most 
adherent districts have succeeded in part by focusing on language that highlights individual student rights (Meyer \& Keenan, 2018).

\section{Advocacy Impacts Resiliency}

The overarching goal of the recommendations presented herein is to promote resilience among TGNC college students. Each action aims to align with one or more of Singh's resilience strategies of TGNC persons: evolving a self-generated definition of self, embracing self-worth, awareness of oppression, and connection with a supportive community (Singh, Hays, \& Watson, 2011). Specifically, actions that increase positive social support and self-advocacy promote resiliency, which subsequently decreases anxiety and depression and increases academic success (Bariola et al., 2015; Swanbrow Becker et al., 2017). Broadly, a sense of belonging while in school increases a person's overall sense of well-being; "(r)esiliency is often mistakenly seen as a personal attribute or capacity, which ignores the social and structural factors that create the adversity" (Zeeman et al., 2017, p. 392). Therefore, the goal of these strategies is not to "fix" the individual, but instead to address a problematic system that is causing significant harm to that individual. Thus, it is expected that these campus and class specific recommended practices would not only positively impact the overall culture of the educational environment, but positively impact the learning outcomes for individual students (Bariola, et al., 2015; Bockting, et al., 2013; Meyer, 2015).

\section{Conclusion}

Mental health professionals have a demonstrated track record of effecting positive social change in educational institutions regarding diversity and multiculturalism. This presents a powerful opportunity for these professions to utilize their unique skills, knowledge, and expertise to evolve university and college campuses to better meet the needs of TGNC students. Specifically, mental health professionals can positively impact higher education institutions through directed activities on campus, in classrooms, in research, and in direct service to these individuals. In doing so, the professional obligation of justice and respect for others is upheld and thus ensures that institutions of learning are structured to provide the most fertile ground upon which every mind may flourish.

\section{References}

American Counseling Association. (2014). ACA Code of ethics. Alexandria, VA: Author.

American Psychological Association (APA). (2002). Ethical principles of psychologists and code of conduct. American Psychologist, 57, 1060-1073.

American Psychological Association (APA). (2015). Guidelines for psychological practice with transgender and gender nonconforming people. American Psychologist, 70, 832-864.

Baker, K. E. (2017). The future of transgender coverage. New England Journal of Medicine, 316, 1801-1804.

Bariola, E., Lyons, A., Leonard, W., Pitts, M., Badcock, P., \& Couch, M. (2015). Demographic and psychosocial factors associated with psychological distress and resilience among transgender individuals. American Journal of Public Health, 105, 2108-2116.

Bockting, W. O., Miner, M. H., Swinburne Romine, R. E., Hamilton, A., \& Coleman, E. (2013). Stigma, mental health, and resilience in an online sample of the U.S. transgender population. American Journal of Public Health, 103, 943-951. 
Bouman, W. P., Davey, A., Meyer, C., Witcomb, G. L., \& Arcelus, J. (2016). Predictors of psychological well-being among treatment seeking transgender individuals. Sexual \& Relationship Therapy, 31, 359-375.

Bradford, J., Reisner, S. L., Honnold, J. A., \& Xavier, J. (2013). Experiences of transgender-related discrimination and implications for health: Results from the Virginia Transgender Health Initiative Study. American Journal of Public Health, 103, 1820-1829.

BrckaLorenz, A., Garvey, J. C., Hurtado, S. S., \& Latopolski, K. (2017). High-impact practices and student-faculty interactions for gender-variant students. Journal of Diversity in Higher Education, 10, 350.

Brewster, M. E., Velez, B. L., Mennicke, A., \& Tebbe, E. (2014). Voices from beyond: A thematic content analysis of transgender employees' workplace experiences. Psychology of Sexual Orientation and Gender Diversity, 1, 159-169.

Budge, S. L., Adelson, J. L., \& Howard, K. A. (2013). Anxiety and depression in transgender individuals: The roles of transition status, loss, social support, and coping. Journal of Consulting and Clinical Psychology, 81, 545.

Burnes, T. R., Singh, A. A., Harper, A. J., Harper, B., Maxon-Kann, W., Pickering, D. L., \& Hosea, J. U. L. I. A. (2010). American Counseling Association: Competencies for counseling with transgender clients. Journal of LGBT Issues in Counseling, 4, 135-159.

Cahill, S., \& Makadon, H. (2014). Sexual orientation and gender identity data collection in clinical settings and in electronic health records: A key to ending LGBT health disparities. LGBT Health, 1, 34-41.

Cannon, Y., Speedlin, S., Avera, J., Robertson, D., Ingram, M., \& Prado, A. (2017). Transition, connection, disconnection, and social media: Examining the digital lived experiences of transgender individuals. Journal of LGBT Issues in Counseling, 11, 68-87.

Carmel, T. C., \& Erickson-Schroth, L. (2016). Mental health and the transgender population. Journal of Psychosocial Nursing and Mental Health Services, 54, 44-48.

Chernin, P. (Producer), \& Melfi, T. (Director). (2016). Hidden figures [Motion picture]. United States: Twentieth Century Fox.

Coleman, E., Bockting, W., Botzer, M., Cohen-Kettenis, P., DeCuypere, G., Feldman, J., ... Zucker, K. (2012). Standards of care for the health of transsexual, transgender, and gendernonconforming people, Version 7. International Journal of Transgenderism, 13, 165-232.

Connolly, M. D., Zervos, M. J., Barone, C. J., Johnson, C. C., \& Joseph, C. L. M. (2016). The mental health of transgender youth: Advances in understanding. Journal of Adolescent Health, 59, $489-495$.

Deutsch, M. B., \& Buchholz, D. (2015). Electronic health records and transgender patients: Practical recommendations for the collection of gender identity data. Journal of General Internal Medicine, 30, 843-847.

Grant, J. M., Mottet, L. A., Tanis, J. J., \& Min, D. (2011). Injustice at every turn: A report of the National Transgender Discrimination Survey. Washington, DC: National Center for Transgender Equality and National Gay and Lesbian Task Force. Retrieved from https://www.hivlawandpolicy.org/sites/default/files/Injustice\%20at\%20Every\%20Turn.pdf

Gray, A., Crandall, R. E., \& Tongsri, J. (2018). Transgender student-athletes and their inclusion in intercollegiate athletics. New Directions for Student Services, 2018, 43-53. 
Green, E. R. (2014). Does teaching transgender content effectively reduce anti-transgender prejudice? The findings from a national study. Chester, PA: Widener University, Center for Human Sexuality Studies.

Hendricks, M. L., \& Testa, R. J. (2012). A conceptual framework for clinical work with transgender and gender nonconforming clients: An adaptation of the minority stress model. Professional Psychology: Research and Practice, 43, 460-467.

James, S. E., Herman, J. L., Rankin, S., Keisling, M., Mottt, L., \& Anafi, M. A. (2016). The report of the 2015 U.S. Transgender Survey. Washington, DC: National Center for Transgender Equality.

Johnston, M. S. (2016). "Until that magical day...no campus is safe": Reflections on how transgender students experience gender and stigma on campus. Reflective Practice, 17, 143-158.

Jones, T. (2017). Evidence affirming school supports for Australian transgender and gender diverse students. Sexual Health, 14, 412-416.

Kanamori, Y., Cornelius-White, J. H. D., Pegors, T. K., Daniel, T., \& Hulgus, J. (2017). Development and validation of the Transgender Attitudes and Beliefs Scale. Archives of Sexual Behavior, $46,1503-1515$.

Kite, M. E., \& Bryant-Lees, K. B. (2016). Historical and contemporary attitudes toward homosexuality. Teaching of Psychology, 43, 164-170.

Meyer, I. H. (2015). Resilience in the study of minority stress and health of sexual and gender minorities. Psychology of Sexual Orientation and Gender Diversity, 2, 209-213.

Meyer, E. J., \& Keenan, H. (2018). Can policies help schools affirm gender diversity? A policy archaeology of transgender-inclusive policies in California schools. Gender and Education, 30, 736-753. doi:10.1080/09540253.2018.1483490

Morris, J. F., \& Van Raalte, J. L. (2016). Transgender and gender nonconforming athletes: Creating safe spaces for all. Journal of Sport Psychology in Action, 7, 121-132.

National Association of Social Workers. (n.d.). Code of ethics of the National Association of Social Workers. Retrieved from https://www.socialworkers.org/About/Ethics/Code-of-Ethics/Code-ofEthics-English

Nicolazzo, Z. (2016). "Just go in looking good": The resilience, resistance, and kinship-building of trans* college students. Journal of College Student Development, 57, 538-556.

Nicolazzo, Z., \& Marine, S. B. (2015). "It will change if people keep talking": Trans* students in college and university housing. Journal of College and University Student Housing, 42, 160177.

Pryor, J. T. (2015). Out in the classroom: Transgender student experiences at a large public university. Journal of College Student Development, 56, 440-455.

Schmider, A. (2016, November 9). 2016 was the deadliest year on record for transgender people. Retrieved from https://www.glaad.org/blog/2016-was-deadliest-year-record-transgenderpeople

Seelman, K. L. (2016). Transgender adults' access to college bathrooms and housing and the relationship to suicidality. Journal of Homosexuality, 63, 1-22.

Singh, A. A., Hays, D. G., \& Watson, L. S. (2011). Strength in the face of Adversity: Resilience strategies of transgender individuals. Journal of Counseling and Development, 89, 20-27. 
Singh, A. A., Meng, S. E., \& Hansen, A. (2013). "It's already hard enough being a student": Developing affirming college environments for trans youth. Journal of LGBT Youth, 10, 208223.

Singh, A. A., Meng, S. E., \& Hansen, A. W. (2014). "I am my own gender": Resilience strategies of trans youth. Journal of Counseling and Development, 92, 208-218.

Snyder, T. D., de Brey, C., \& Dillow, S. A. (2016). Digest of education statistics 2014 (50th ed.; NCES 2016-006). Washington, DC: National Center for Education Statistics. Retrieved from https://eric.ed.gov/?id=ED565675

Swanbrow Becker, M. A., Nemeth Roberts, S. F., Ritts, S. M., Branagan, W. T., Warner, A. R., \& Clark, S. L. (2017). Supporting transgender college students: Implications for clinical intervention and campus prevention. Journal of College Student Psychotherapy, 31, 155.

Testa, R. J., Jimenez, C. L., \& Rankin, S. (2014). Risk and resilience during transgender identity development: The effects of awareness and engagement with other transgender people on affect. Journal of Gay \& Lesbian Mental Health, 18, 31-46.

Woodford, M. R., Weber, G., Nicolazzo, Z., Hunt, R., Kulick, A., Coleman, T., ... \& Renn, K. A. (2018). Depression and attempted suicide among LGBTQ college students: Fostering resilience to the effects of heterosexism and cisgenderism on campus. Journal of College Student Development, 59, 421-438.

Zeeman, L., Aranda, K., Sherriff, N., \& Cocking, C. (2017). Promoting resilience and emotional wellbeing of transgender young people: Research at the intersections of gender and sexuality. Journal of Youth Studies, 20, 382-397.

The Journal of Social, Behavioral, and Health Sciences is an open-access, peer-reviewed, online interdisciplinary journal focusing on research findings that address contemporary national and international issues. Its objectives are to (a) encourage dialogue between scholars and practitioners in the social, behavioral, and health sciences that fosters the integration of research with practice; (b) promote innovative models of interdisciplinary collaboration among the social, behavioral, and health sciences that address complex social problems; and (c) inform the relationship between practice and research in the social, behavioral, and health sciences.

Walden University Publishing: http://www.publishing.waldenu.edu 